\title{
Early patterns of recovery from disturbance in intertidal algal assemblages: consistency across regions within a marine province
}

\author{
Gustavo M. Martins ${ }^{1,2, *}$, Stuart R. Jenkins ${ }^{3}$, Rubén Ramírez ${ }^{4}$, Fernando Tuya ${ }^{4}$, \\ Ana I. Neto ${ }^{1,2}$, Francisco Arenas ${ }^{1}$ \\ ${ }^{1}$ Interdisciplinary Centre of Marine and Environmental Research (CIIMAR/CIMAR), University of Porto, Rua dos Bragas 289, \\ 4050-123 Porto, Portugal \\ ${ }^{2}$ Centro de Investigação de Recursos Naturais dos Açores (CIRN), Departamento Biologia, Universidade dos Açores, \\ 9501-801 Ponta Delgada, S. Miguel, Açores, Portugal \\ ${ }^{3}$ School of Ocean Sciences, Bangor University, Menai Bridge, Anglesey, UK \\ ${ }^{4}$ Grupo en Biodiversidad y Conservación, Marine Sciences Faculty, Universidad de Las Palmas de Gran Canaria, Las Palmas, \\ Canary Islands, Spain
}

\begin{abstract}
Disturbance and the subsequent rate and pattern of recovery have long been recognised as important drivers of community structure. Community recovery is affected by processes operating at local and regional scales, yet the examination of community-level responses to a standardised disturbance at regional scales (i.e. among regions under different environmental conditions) has seldom been attempted. Here, we mechanically disturbed rocky intertidal lower-shore algal-dominated assemblages at 3 locations within each of 3 different regions within the Lusitanian biogeographical province (Azores, northern Portugal and the Canary Islands). All organisms were cleared from experimental plots and succession followed over a period of $12 \mathrm{mo}$, at which time we formally compared the assemblage structure to that of unmanipulated controls. Early patterns of recovery of disturbed communities varied among regions and were positively influenced by temperature, but not by regional species richness. Different components of the assemblage responded differently to disturbance. Regional differences in the relative abundance and identity of species had a key influence on the overall assemblage recovery. This study highlights how regional-scale differences in environmental conditions and species pools are important determinants of recovery of disturbed communities.
\end{abstract}

KEY WORDS: Perturbation - Stability · Community structure - Spatial scales - Species richness · Species identity $\cdot$ Algae $\cdot$ Lusitania

Resale or republication not permitted without written consent of the publisher

\section{INTRODUCTION}

The key role of disturbance as a driver of community structure has been the focus of much ecological research since Dayton's seminal paper was published more than 4 decades ago (Dayton 1971). However, understanding the mechanisms that influence the recovery of populations and communities from disturbances has received renewed interest, given the unprecedented rates of human-driven disturbance to natural ecosystems. A vast number of studies have uncovered the influence of multiple factors on rates of community recovery. For instance, Petraitis \& Latham (1999) and Dudgeon \& Petraitis (2001) observed 2 structurally and functionally distinct community types following simulation of different scales of disturbance from ice scour, one dominated by the canopy-forming alga Ascophyllum nodosum and the other by filter feeders such as mussels and barnacles. Different community types can also have different recovery 
rates. For example, while patches of $A$. nodosum had not yet fully recovered $11 \mathrm{yr}$ after disturbance (Jenkins et al. 2004), impressive rates of recovery for turfforming algae $(<1 \mathrm{yr})$ have been observed (Airoldi 1998). These differences likely reflect species-specific life-history traits (e.g. vegetative regrowth vs. colonisation from waterborne propagules).

Species richness can also influence community recovery. For example, Tilman \& Downing (1994) found that richer assemblages of plants had a greater resistance and resilience to a severe drought (disturbance), while Aquilino \& Stachowicz (2012) found that the presence of herbivores and the diversity of the surrounding assemblage also had positive influences on the rates of assemblage recovery of disturbed plots. In addition, Wilson \& Tilman (2002) found that species richness was influenced by location within a fertility-disturbance matrix. Specifically, they found a hump-shaped relationship between richness and disturbance at low levels of productivity, but no relationship was apparent at high levels of productivity. These results suggest that disturbance and productivity can have interactive effects on community structure via changes in species richness that could, in turn, influence community recovery.

Despite general acknowledgment of the importance of scale in ecological studies, the majority of work is still dominated by small-scale experiments carried out in a few locations, despite calls for the need to scale up from local to biogeographical scales (Hewitt et al. 2007). This is important because regional-scale variation in environmental factors can modify the effects of local-scale processes (Navarrete et al. 2005) and also because species with wide geographical distributions can show significant differences in recovery rates among geographically different populations (Sisodia \& Singh 2010, Crowe et al. 2013). One way to scale up is to replicate experiments across large spatial scales, the so-called 'comparative-experimental approach' (Menge et al. 2002). The benefit of such an approach is that large-scale variability in environmental conditions (e.g. variation in productivity) and ecological processes operating at small scales (e.g. competition), which result in a range of effects on patterns of community structure and dynamics, can be accounted for (Hewitt et al. 2007) and thus provide a more holistic understanding of ecological ecosystems. A few studies illustrate this point. For instance, in a manipulative study replicated at 5 locations spanning $17^{\circ}$ of latitude, Coleman et al. (2006) found that grazing by limpets is a key process in rocky shore ecosystems over much of continental Europe by controlling the abundance of algae at mid-shore levels. Yet, grazing by limpets had contrasting effects on assemblage variability over the latitudinal gradient, increasing towards the northern locations. Another study found that both assemblage stability and compensatory dynamics as a response to the loss of canopy-forming algae varied regionally, being generally weaker towards higher latitudes (Bulleri et al. 2012). The benefits of broadscale replication of small-scale studies have now been made clear, and output from such work is enhancing the predictive capacity of current ecological models (Navarrete et al. 2005).

We applied the comparative-experimental approach by examining early patterns of community recovery following disturbance of low shore intertidal assemblages in 3 regions within the marine province of Lusitania: the northern coast of Portugal and the Azores and Canary archipelagos (Fig. 1). Northern Portugal is a transition zone between the Atlantic and Mediterranean biogeographical regions (Lima et al. 2007, Tuya et al. 2012) and supports a highly diverse biota where many macroalgal species have their latitudinal limits of distribution (Araújo et al. 2009a and references therein). Moreover, the Atlantic coast of Portugal is within the northern zone of the Canary Upwelling System, 1 of the 4 major upwelling regions in the world (see Santos et al. 2011 and references therein). The Canary Islands and the Azores are oceanic archipelagos belonging to the Macaronesia region. The 2 archipelagos differ in that the Canary Islands are considered a hotspot for biodiversity, whereas the Azores support a comparatively less diverse biota due to the high degree of isolation (>1000 km from the mainland) and recent geological age $(<8 \mathrm{M}$ yr; Hawkins et al. 2000, Tuya \& Haroun 2009). Unlike the adjacent continental mass, the Canary Islands and the Azores are generally surrounded by oligotrophic oceanic waters (Martins et al. 2007), although productivity can be occasionally high due to island effects (see Hernández-Léon 1988).

Through experimental simulation of disturbance, followed by observations over $12 \mathrm{mo}$, we tested the hypothesis that disturbance would lead to different regional-scale patterns of recovery and hence differences among regions in the magnitude or extent to which disturbed communities differ from undisturbed ones in terms of species composition, richness and relative abundance of key taxa. We tested the influence of regional richness, productivity and seawater temperature on a general metric of assemblage recovery (dissimilarity in assemblage structure between disturbed and undisturbed areas). We further explored the data to examine what components of 

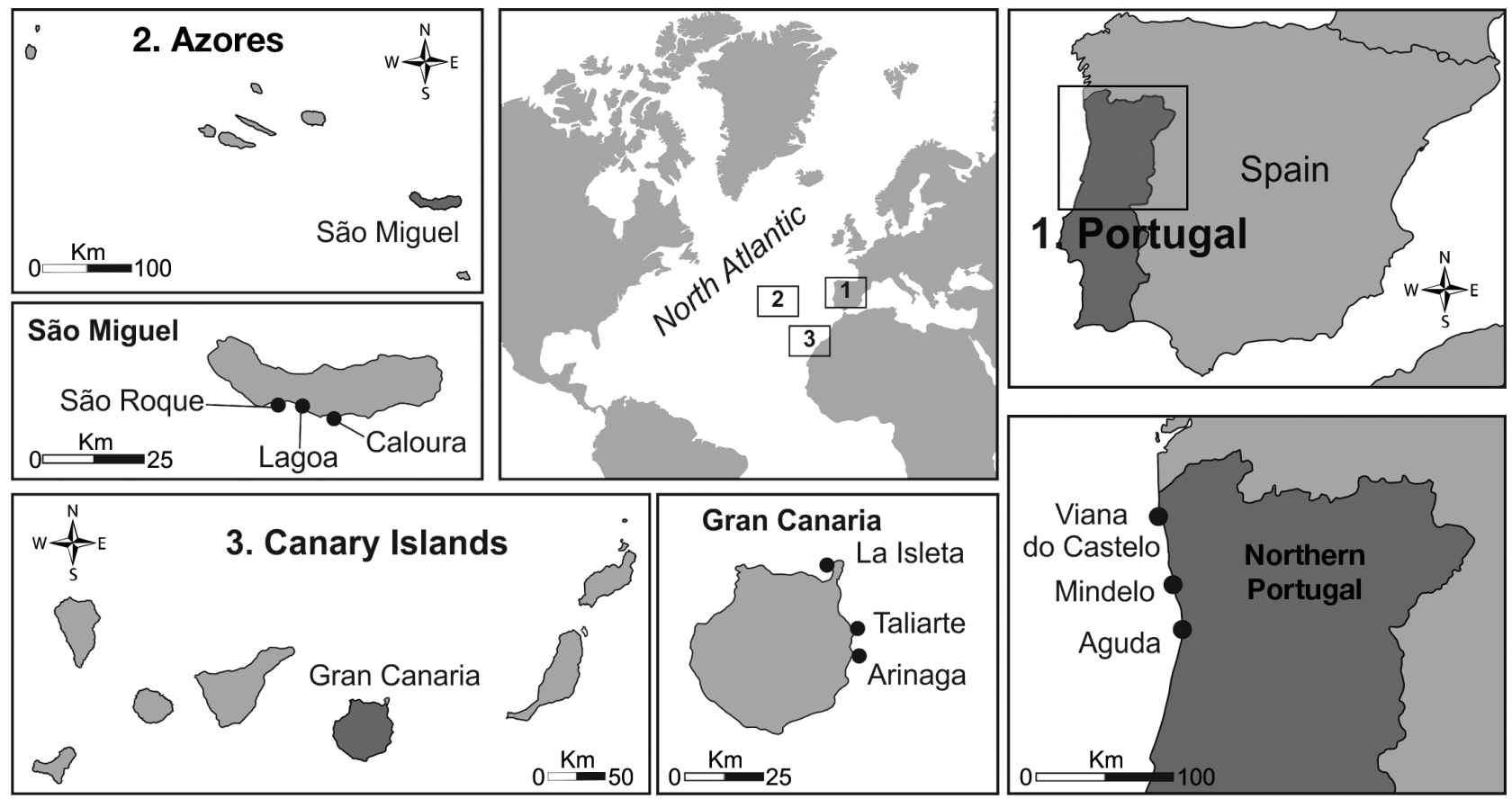

Fig. 1. Sampled locations in (1) northern Portugal, (2) Azores and (3) the Canary Islands

diversity (e.g. composition) may explain differences in regional patterns of assemblage recovery. This strategy allowed us to integrate natural history and environmental heterogeneity in our understanding of patterns of assemblage recovery and thus assess the generality in recovery over a regional scale.

\section{MATERIALS AND METHODS}

\section{Study sites}

The study was undertaken on lower-shore algaldominated (approximately at the mean low water height of each region) sites of the rocky intertidal at 3 locations (ranging from 6 to $70 \mathrm{~km}$ apart) in each of 3 regions: northern Portugal, the Azores and the Canary Islands (Fig. 1). All locations were selected to be as similar in habitat as possible and hence all locations were directly open to the sea and exposed to wave action. All experimental plots were established on gently sloping bedrock. The 3 regions studied vary in environmental conditions and in the diversity of the biota (Table 1). In northern Portugal, the lower shore is a patchy mosaic of algae dominated by coarsely-branched algae (e.g. Osmundea spp., Dictyota spp.) or the leathery brown alga Bifurcaria bifurcata. The Azores and the Canaries are typically dominated by articulated corallines (e.g. Corallina elongata, Jania rubens) and algal turfs consisting of coarsely branched and filamentous algae (e.g. Palisada perforata, Chaetomorpha spp., Osmundea spp.). At this shore level, animals include Mytilus sp. and Sabellaria alveolata (present only in northern Portugal), chthamalid barnacles, gastropod molluscs (patellid limpets, trochid snails and muricid whelks) and sea urchins (Paracentrotus lividus). These animals were generally rare in our study locations at the chosen shore level.

Table 1. Differences in environmental conditions among regions. Data are typical daily minimum and maximum values through an entire annual cycle. The total number of species for each region (as found in this study) is also included. SST: sea surface temperature

\begin{tabular}{|lccc|}
\hline Region & $\begin{array}{c}\mathrm{SST} \\
\left({ }^{\circ} \mathrm{C}\right)\end{array}$ & $\begin{array}{c}\mathrm{Chl} \mathrm{a} \\
\left(\mathrm{mg} \mathrm{m}^{-3}\right)\end{array}$ & $\begin{array}{c}\text { No. of } \\
\text { species }\end{array}$ \\
\hline Northern Portugal & $11-20^{\mathrm{a}}$ & $0.50-18.50^{\mathrm{a}}$ & 58 \\
Azores (São Miguel) & $14-23^{\mathrm{b}}$ & $0.10-0.27^{\mathrm{c}}$ & 48 \\
Canaries (Gran Canaria) & $18-23^{\mathrm{d}}$ & $0.13-0.35^{\mathrm{e}}$ & 52 \\
& & & \\
& & \\
a Tuya et al. (2012), ${ }^{\mathrm{b}}$ Instituto Hidrográfico (2000), \\
${ }^{\mathrm{c}}$ Amorim (2008), ${ }^{\mathrm{d} N a v a r r o}$ et al. (2012), ${ }^{\mathrm{e}}$ Tuya et al. (2006) \\
\hline
\end{tabular}




\section{Sampling design}

At each location, a stretch of coast roughly $50 \mathrm{~m}$ wide was chosen, and a total of 30 plots $(15 \times 15 \mathrm{~cm})$ were haphazardly established, a minimum of $1 \mathrm{~m}$ apart, on the lower algal-dominated shore in areas of gently sloping and well-drained bedrock. Plots were marked with stainless steel screws driven into the substrate and a plastic tag and then randomly assigned into 1 of 2 treatments: disturbed (15 replicate plots) and control (15 replicate plots). Disturbed plots were cleared of biota by chiseling and scrubbing off all visible biota and blow-torching afterwards. Control plots were left unmanipulated. The chosen size of the disturbances is within the size of gaps easily recognised in the field that are probably the result of a number of processes such as the physical abrasion caused by the movement of nearby boulders, the loss of bedrock as a consequence of high wave action or even the consequence of grazers (e.g. sea urchins). To discern potential differences resulting from timing of disturbance (i.e. season), disturbances were applied at 3 times (April, July and October of 2011). Five replicate plots (of the 15 assigned to the disturbance treatment) were randomly assigned to each time. Preliminary data analyses showed that assemblages developing after disturbances made at different times of the year converged rapidly after a few months of succession in all regions and there was no difference in the structure of 12 mo old disturbed assemblages as well as that of controls related to the timing of disturbance (see Table S1 in the Supplement at www.int-res.com/articles/suppl/m517p131_ supp.pdf). Therefore, for the purpose of this study, data from the 3 starting dates were pooled.

Plots were visually inspected 1, 3, 6, 9 and 12 mo after the disturbance. Algae were quantified by assigning a score of 0 to 4 ( 0 being absent, 4 being full cover) to each taxon within each of the 25 subdivisions of the sampling quadrat $(15 \times 15 \mathrm{~cm})$. The subdivision scores were summed to produce an estimate of percentage cover for each taxon (Dethier et al. 1993). Sampling in northern Portugal, where canopy species were present, was done in 2 layers: canopy and understory algal turf.

Species that were present inside quadrats but whose abundance was less than $1 / 4$ of a subdivision were recorded as present and later assigned an arbitrary cover of $1 \%$. All species were identified in situ to the lowest taxonomic resolution possible. Where in doubt, sample specimens were collected nearby and brought to the laboratory for later identification. Five independent control plots were assigned randomly as controls for each of the seasonal disturbance events and were only sampled at the end of each of the seasonal experiments (corresponding to the 12 mo old disturbed plots).

\section{Data analysis}

Early patterns of assemblage recovery

In order to test whether disturbed assemblages had fully recovered by the end of the study period, we used a 3-way permutational multivariate ANOVA (PERMANOVA) with the factors: Treatment (2 levels: 12 mo old disturbed vs. control; fixed), Region (3 levels, fixed and orthogonal to Treatment) and Location (3 levels, random and nested within Region). The analysis was based on Bray-Curtis similarity matrices calculated from fourth root-transformed data (Quinn $\&$ Keough 2002). Data were graphically represented using non-metric multidimensional scaling.

The extent to which disturbed assemblages recovered was also estimated by calculating the dissimilarity from each disturbed plot at the end of $12 \mathrm{mo}$ to the centroid of the unmanipulated controls also based on Bray-Curtis similarity matrices calculated from fourth root-transformed data (Quinn \& Keough 2002) in a way similar to that described by Donohue et al. (2013) to measure community resistance. To test the hypothesis that the extent of early patterns of assemblage recovery differs among regions, the estimates of Bray-Curtis similarity were analysed using ANOVA as in Donohue et al. (2013). In this case, we used a 2-way ANOVA with the factor Region (3 levels; fixed) and Location (3 levels; random and nested within region). As mentioned above, plots from the 3 timings were pooled, so that a total of 15 replicates (5 replicates $\times 3$ disturbance timings), all 12 mo old, were available for the analyses. Prior to analysis, heterogeneity of variances was tested using Cochran's test and transformations were applied if necessary (Underwood 1997). Student-Newman-Keuls (SNK) tests were used to resolve significant differences within regions.

\section{Regional-scale predictors of early patterns of assemblage recovery}

We used multiple linear regression to examine whether the extent of assemblage recovery (as determined above) varied with regional species richness and sea surface temperature (SST; see Table 1 for 
source data). Productivity level (chlorophyll $a, \mathrm{chl} a$ ) was removed from the predictor variables due to strong collinearity with both regional species richness and SST $(r>10.911)$. Regional species richness used in the analysis was calculated from our dataset by counting the total number of species within each region. This approach was taken to ensure comparability among regions, as regional species richness calculated from published species lists are influenced by variable sampling effort and expertise among regions (Tuya \& Haroun 2009). SST and chl a concentration were not available as raw data (e.g. mean daily SST) for all regions. For some regions, the only information we were able to access was the annual range of values. As a result, we used the median value as the fully trimmed mid-range for each region in the analyses.

\section{Early patterns of recovery and regional-scale differences in diversity}

Species richness, number of rare species and the abundance of macroalgal morpho-functional groups were contrasted between the 12 mo disturbed and control plots using a 3-way mixed model ANOVA with the factors Treatment (2 levels, fixed), Region (3 levels, fixed and orthogonal to Treatment), and Location (3 levels, random and nested within Region). The number of rare species was estimated independently for each region and was defined as the number of species that were present in less than $5 \%$ of all the samples in that region. We found that species frequency (incidence) and abundance were highly correlated $(r=0.83)$, and our definition of rare species included species that had on average an abundance $<6 \%$, which is often regarded as the limit between rare and occasional categories of abundance scales (e.g. ACFOR scale; Crisp \& Southward 1958). The relative proportions of rare species were calculated for each plot. Variation in macroalgal abundance was investigated separately for 6 different morpho-functional groups according to Steneck \& Dethier (1994) and Tuya \& Haroun (2006): sheet-like algae, filamentous algae, coarsely-branched algae, leathery algae, articulated coralline algae and crustose algae.

We also analysed 2 different components of assemblages to test (1) how much of the recovery was due to the presence of species in disturbed plots also found in controls, and (2) how much of the recovery was due to the recuperation of total algal cover in comparison to the control plots. The former was calculated for each disturbed plot as the percentage of species established in the disturbed plot that were also present in control plots (pooled together for the corresponding location within each region). The latter was calculated for each disturbed plot as the percentage of algal cover in disturbed plots relative to the average of controls (for the corresponding location within each region). These data were analysed using 2-way ANOVA as described above.

Although we sampled disturbed plots through time, we restricted our comparisons and analyses between disturbed and control plots to the last sampling time (12 mo after the initial disturbance) because control plots were sampled only at 12 mo. Data from other sampling times were used to describe successional patterns.

\section{RESULTS}

\section{Early patterns of assemblage recovery: relationship with 'environmental' data}

In total, we recorded 95 species of algae in our study plots (see Table S2 in the Supplement). Northern Portugal had the overall greatest richness (58 species), followed by the Canary Islands (52 species) and the Azores (48 species; Table 1, Table S2). Colonisation of disturbed plots was rapid and succession occurred quickly (see Fig. S1 in the Supplement).

By the end of the study period (12 mo), disturbed assemblages had not fully recovered in any of the 3 regions (Fig. 2, PERMANOVA: significant Treatment $\times$ Region interaction, $\mathrm{p}<0.01$; pairwise comparisons

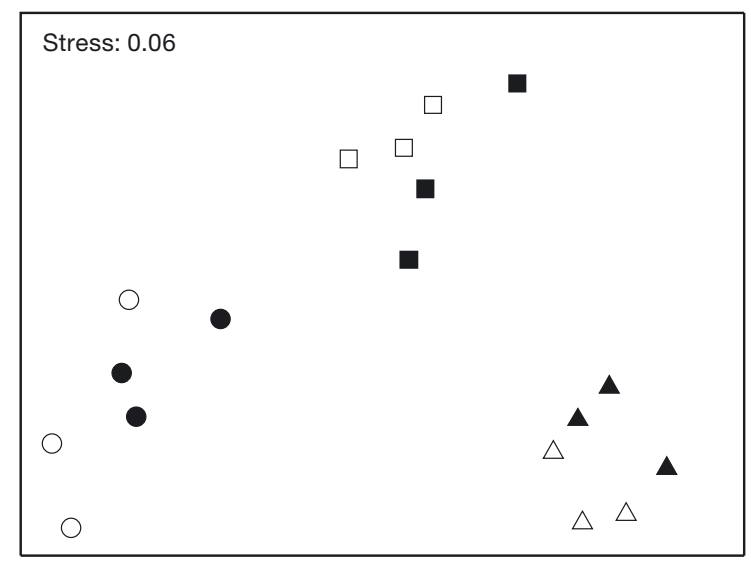

Fig. 2. Non-metric multidimensional scaling comparing the assemblage structure in 12 mo old disturbed plots (black symbols) and unmanipulated controls (open symbols) in each of the 3 regions: northern Portugal (circles), Azores (squares), Canary Islands (triangles). Points within each region represent the centroid for each of the 3 locations, respectively 
showed that assemblage structure of disturbed and control plots differed with $\mathrm{p}<0.05$ in all regions).

Similarity between 12 mo old disturbed and control plots (recovery) varied significantly among regions (Fig. 3, Table 2). The Canary Islands showed the greatest similarity; disturbed assemblages had a mean $( \pm \mathrm{SE})$ percentage similarity of $61.4 \pm 1.5 \%$ relative to controls (Fig. 3). Early patterns of assemblage recovery in northern Portugal were significantly slower, with a mean percentage similarity of $36.0 \pm$ $2.1 \%$ between disturbed and control plots (Fig. 3). Early patterns of recovery in the Azores were halfway between those found in the Canary Islands and in northern Portugal and not significantly different from either, with a mean percentage similarity of $48.2 \pm 2.4 \%$ between disturbed and control plots (Fig. 3).

Multiple regression analysis showed that the overall model significantly deviated from random and that temperature, but not richness, explained a significant proportion of the variation (Table 3 ).

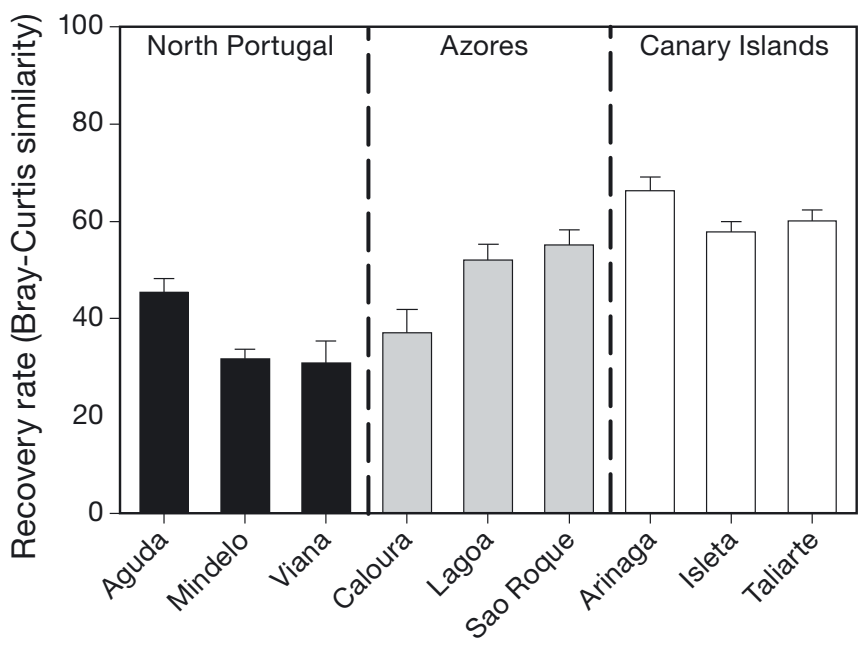

Fig. 3. Mean (+SE) Bray-Curtis similarity in assemblage structure between the 12 mo old disturbed plots and the centroid of the corresponding unmanipulated controls

Table 2. Two-way ANOVA comparing the similarity between 12 mo old disturbed plots and controls among regions and locations within regions (NP: northern Portugal; AZ: Azores;

CI: Canary Islands). SNK: Student-Newman-Keuls test

\begin{tabular}{|lcrrc|}
\hline Source & df & MS & $F$ & $p$ \\
\hline Region & 2 & 7253.48 & 8.00 & $<0.05$ \\
Location (Region) & 6 & 906.71 & 5.92 & $<0.001$ \\
Residual & 126 & 153.22 & \\
Cochran's & \multicolumn{4}{c}{ C $=0.21$} \\
Transformation & \multicolumn{4}{c}{ None $=\mathrm{CI}, \mathrm{AZ}=\mathrm{NP}, \mathrm{CI}>\mathrm{NP}$} \\
SNK for Region & \multicolumn{4}{c}{} \\
\hline
\end{tabular}

Table 3. Multiple regression comparing the effects regionalscale richness and sea surface temperature $\left(\mathrm{SST},{ }^{\circ} \mathrm{C}\right.$ ) on the mean similarity between 12 mo old disturbed and control plots. The concentration of chlorophyll a was excluded due to high collinearity

\begin{tabular}{|lrrcc}
\hline Source & Estimate & SE & $t$ & $\mathrm{p}$ \\
\hline Intercept & -80.46 & 70.71 & -1.138 & 0.2986 \\
Regional richness & 0.49 & 0.86 & 0.573 & 0.5877 \\
SST & 5.67 & 1.73 & 3.285 & 0.0167
\end{tabular}

Model: $F=8.035, \mathrm{df}=6, \mathrm{p}=0.020, \mathrm{r}^{2}=0.73$

\section{Early patterns of assemblage recovery and regional-scale variation in diversity}

Twelve months post disturbance, there were regional-scale differences in the richness between disturbed and control plots (Fig. 4, Table 4). SNK analysis revealed that mean plot richness in disturbed and control plots was similar in both the Azores and the Canary Islands, whereas in northern Portugal, disturbed plots supported a significantly lower richness compared to undisturbed control plots. There was also regional variation in the percentage of those species found in controls that were also present in disturbed plots (Table 5). In the Azores and Canary Islands, $31 \%$ and $36 \%$, respectively, of the species present in control plots were also present in disturbed plots 12 mo post disturbance, but in northern Portugal this figure was significantly lower at only $19 \%$ (Fig. 5, Table 5). Regional-scale differences were also observed in total cover of algae in disturbed plots in relation to controls (Table 5). Again, total algal cover in

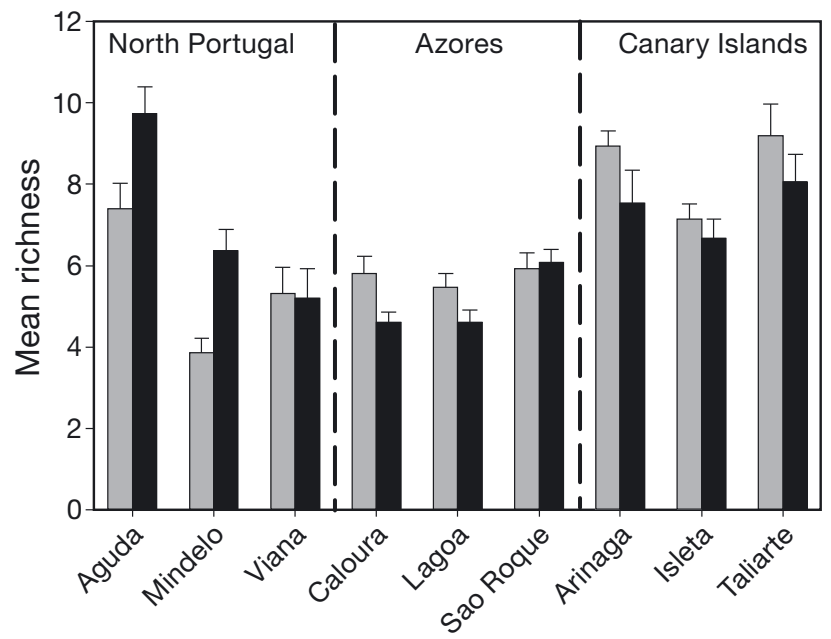

Fig. 4. Mean (+SE) algal richness in 12 mo old disturbed plots (grey bars) and unmanipulated controls (black bars) 
Table 4. Three-way ANOVA comparing the richness and the relative number (\%) of rare species between 12 mo old disturbed plots (12) and controls (C) across regions (Re) and locations within regions $(\mathrm{Lo}(\mathrm{Re}))$. Region codes as in Table 2. ${ }^{*} \mathrm{p}<0.05$, ${ }^{* *} \mathrm{p}<0.01,{ }^{* * *} \mathrm{p}<0.001$. SNK: Student-Newman-Keuls test

\begin{tabular}{|c|c|c|c|c|c|}
\hline \multirow[t]{2}{*}{ Source } & \multirow[t]{2}{*}{ df } & \multicolumn{2}{|c|}{ Richness } & \multicolumn{2}{|c|}{$\%$ of rare species } \\
\hline & & MS & $F$ & MS & $F$ \\
\hline 12 vs. C & 1 & 0.13 & 0.02 & 0.01 & 0.53 \\
\hline $\operatorname{Re}$ & 2 & 145.67 & 2.96 & $<0.01$ & 0.08 \\
\hline Lo(Re) & 6 & 49.13 & $11.29^{* * *}$ & 0.04 & $3.14^{* *}$ \\
\hline 12 vs. $\mathrm{C} \times \mathrm{Re}$ & 2 & 41.54 & $6.44^{*}$ & $<0.01$ & 1.16 \\
\hline 12 vs. $\mathrm{C} \times \mathrm{Lo}(\mathrm{Re})$ & 6 & 6.35 & 1.48 & 0.01 & 0.83 \\
\hline Residual & 252 & 4.35 & 0.01 & & \\
\hline Cochran's & & \multicolumn{2}{|c|}{$C=0.12$} & \multicolumn{2}{|c|}{$C=0.13$} \\
\hline Transformation & & \multicolumn{2}{|c|}{ None } & & ne \\
\hline SNK tests & & \multicolumn{4}{|c|}{$\begin{array}{c}12 \text { vs. } \mathrm{C} \times \text { Re interaction } \\
\text { NP: } 12<\mathrm{C} \\
\text { AZ: } 12=\mathrm{C} \\
\text { CI: } 12=\mathrm{C}\end{array}$} \\
\hline
\end{tabular}

Table 5. Two-way ANOVA comparing the relative number of species present in disturbed plots and total algal cover in relation to undisturbed control plots. Region codes as in Table 2. ${ }^{*} \mathrm{p}<$ $0.05,{ }^{* *} \mathrm{p}<0.01,{ }^{* * *} \mathrm{p}<0.001$. SNK: Student-Newman-Keuls test

\begin{tabular}{|lccccc|}
\hline Source & df & \multicolumn{2}{c|}{ Relative numbers } & \multicolumn{2}{c|}{ Relative } \\
& & \multicolumn{2}{c}{ of species } & \multicolumn{2}{c|}{ algal cover } \\
& \multicolumn{2}{c}{ MS } & $F$ & MS & $F$ \\
\hline Re & 2 & 3427.31 & $12.25^{* *}$ & 6772.53 & $9.05^{*}$ \\
Lo (Re) & 6 & 279.87 & $3.66^{* *}$ & 748.74 & 1.05 \\
Residual & 126 & 76.47 & 711.20 \\
Cochran's & \multicolumn{2}{c}{$C=0.19$} & $C=0.20$ \\
Transformation & \multicolumn{2}{c}{ None } & None \\
SNK for Regions & \multicolumn{2}{c}{$\mathrm{AZ}=\mathrm{CI}>\mathrm{NP}$} & $\mathrm{AZ}=\mathrm{Np}<\mathrm{CI}$ \\
& \multicolumn{3}{c}{} \\
\hline
\end{tabular}

disturbed plots in the Canary Islands was more similar to controls compared to the situation in northern Portugal (Fig. 5). Unlike the case found for the number of species, however, total algal cover in disturbed plots in the Azores was still relatively low and more similar to that found in northern Portugal (Fig. 5, Table 5). In other words, disturbed plots in the Canary Islands were very similar to control plots both in terms of species composition and total algal abundance cover. In contrast, disturbed plots in northern Portugal exhibited a much more dissimilar structure in terms of species composition and total algal cover. In the Azores, disturbed plots were similar to controls in terms of species composition, but not in terms of the total algal abundance.

Adding to the above, the proportion of rare species was similar in 12 mo old disturbed and control plots,
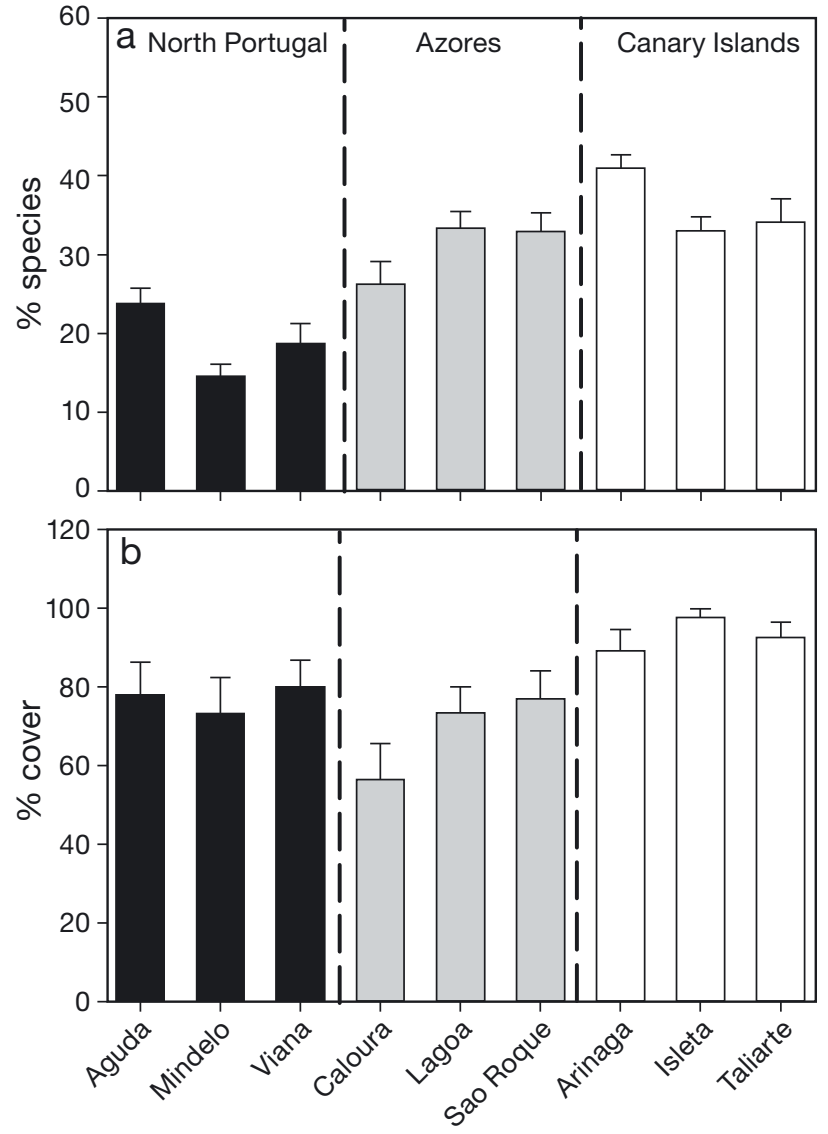

Fig. 5. Mean (+SE) percentage of (a) number of species found in disturbed plots as a function of controls and (b) algal cover in disturbed plots as a function of controls. For further details, see 'Results'

and this result was consistent among regions (see Table 4), suggesting that rare species were not responsible for the lower similarity found between disturbed and control plots in northern Portugal, and to a smaller extent, in the Azores.

\section{Early patterns of assemblage recovery and regional-scale variation in macroalgal morpho-functional groups}

Twelve months after simulated disturbance, differences in the abundance of algae between disturbed and control plots varied among regions only for filamentous algae (significant '12 vs. $\mathrm{C} \times$ Region' interaction, Fig. 6, Table 6). SNK analyses showed that filamentous algae were significantly more abundant in disturbed plots in the Azores, less abundant in disturbed plots in northern Portugal and similarly abundant in disturbed and control plots in the Canary Islands. Encrusting 
a) Sheet-like algae

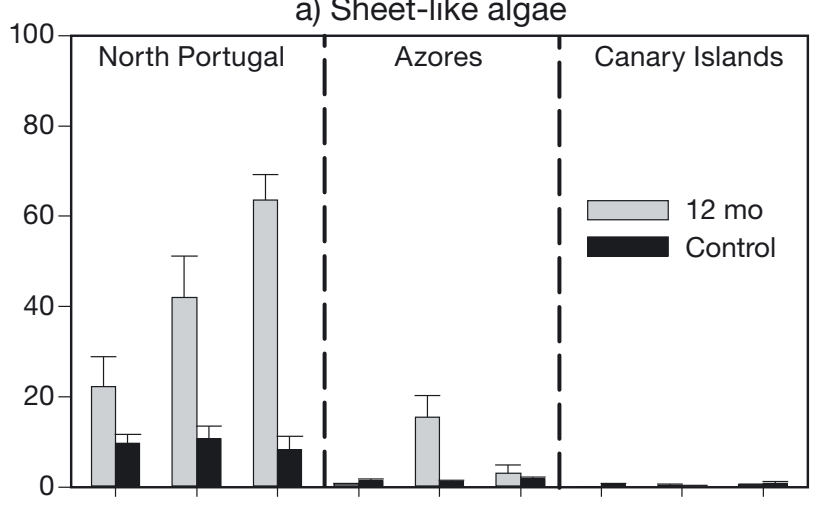

c) Coarsely-branched algae

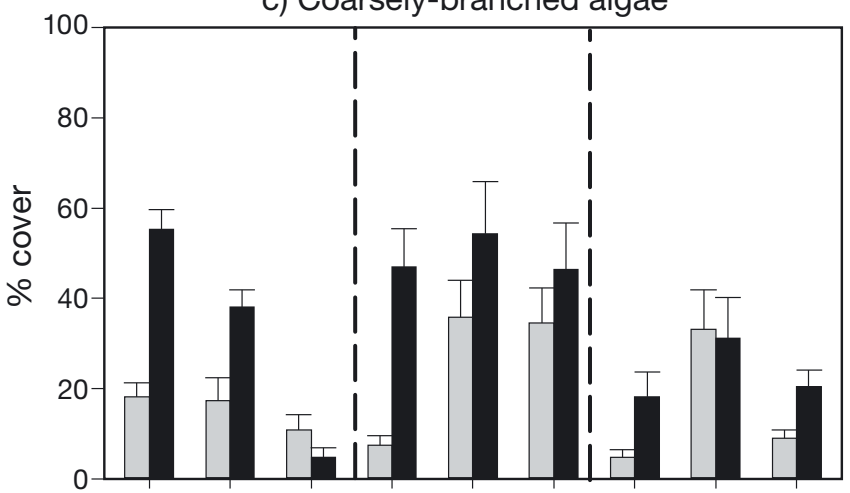

e) Articulated coralline algae

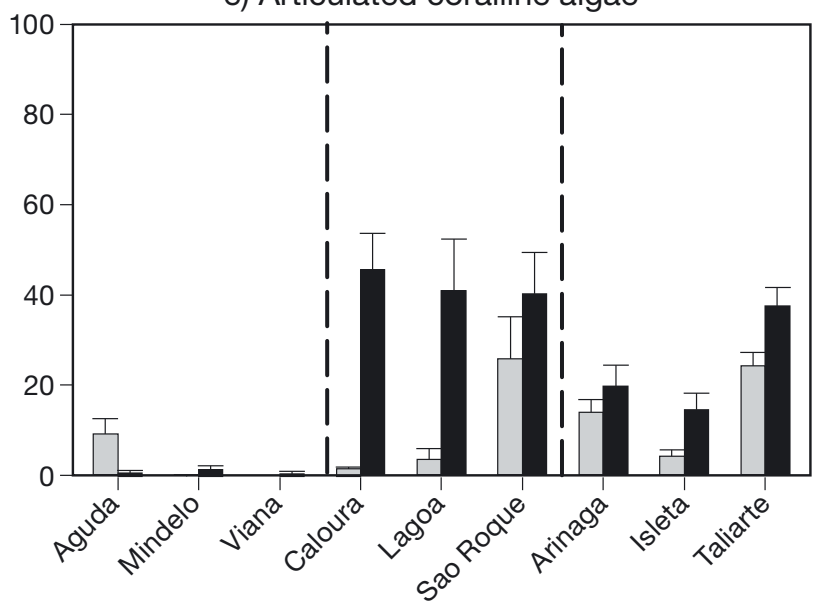

b) Filamentous algae

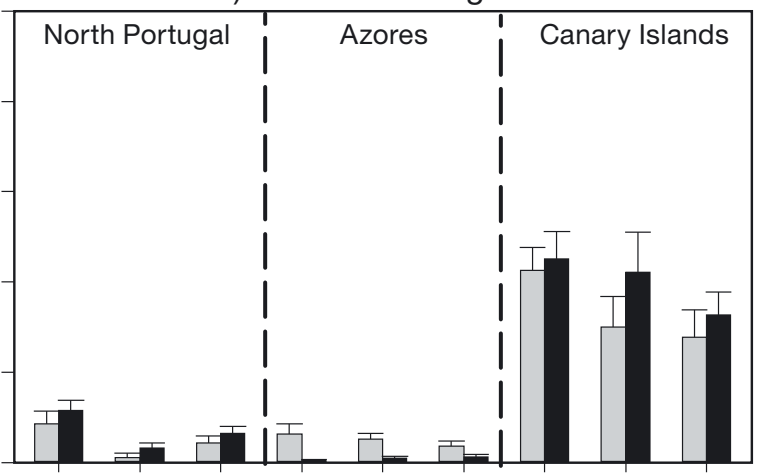

d) Leathery algae

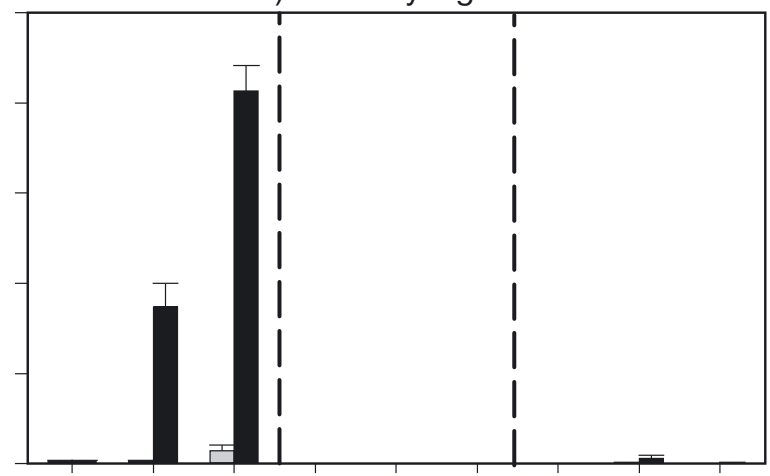

f) Crustose algae

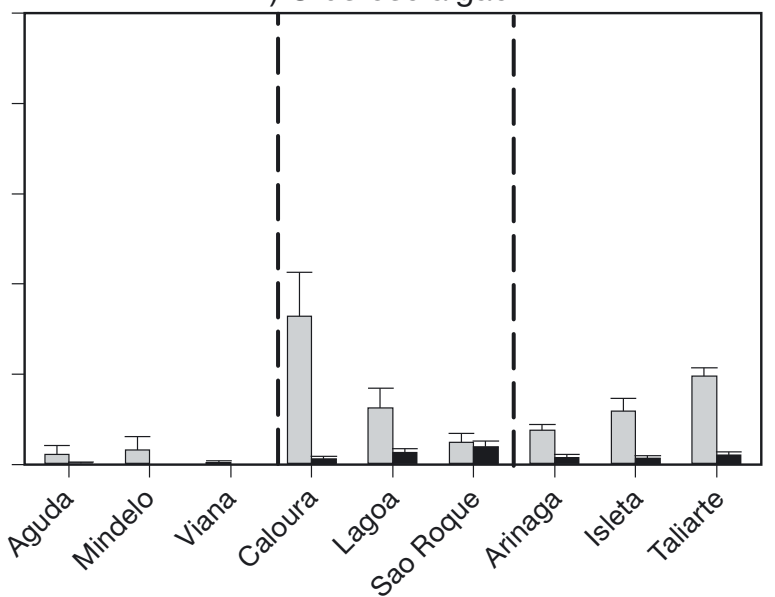

Fig. 6. Mean (+SE) percentage cover of macroalgal morphological groups in 12 mo old disturbed plots (grey bars) and unmanipulated controls (black bars): (a) sheet-like algae, (b) filamentous algae, (c) coarsely-branched algae, (d) leathery algae, (e) articulated coralline algae and (f) crustose algae

algae were significantly more abundant in the 12 mo old disturbed plots, and this was consistent across regions (Fig. 6, Table 6). For the remaining macroalgal groups (articulated coralline, coarsely branched, leathery algae and sheet-like algae), differences in the abundance between disturbed and control plots varied among locations, but not among regions (Fig. 6, Table 6).

\section{DISCUSSION}

Early patterns of assemblage recovery differed among regions. Similarity between disturbed (12 mo old) and control plots was greatest in the southernmost region (Canary Islands) and lowest in the northernmost region (northern Portugal), with the Azores showing an intermediate scenario. Similarity be- 


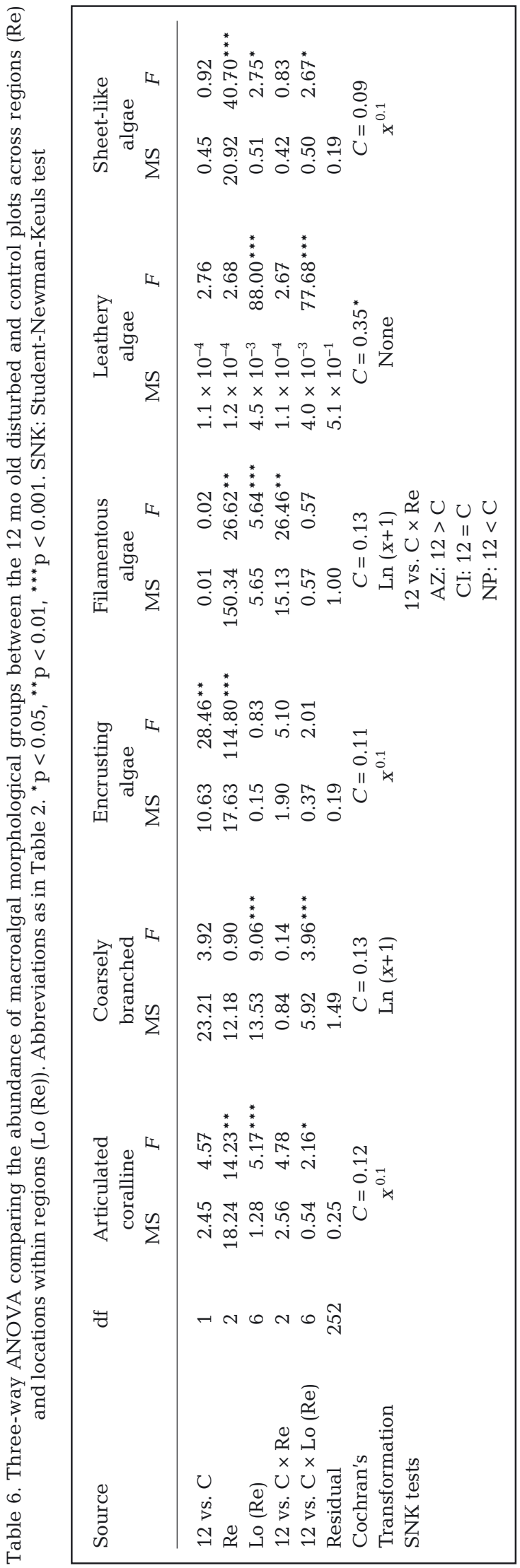

tween disturbed and control plots was positively influenced by SST, but not by regional species pool. Although our observational approach cannot be used to infer causality, our results do not support the general idea that recovery should be greater (or faster) in richer communities (Tilman \& Downing 1994, Aquilino \& Stachowicz 2012). This is potentially a consequence of the limited variation in regional species richness (10 species difference between the richest and poorest region). It should also be noted that our study only concerns early patterns of community assembly and that the influence of regional species richness might become more important during later stages of the community assembly process. Another possibility is that regional-scale variation in species identities (or even the frequency of species occurrence) is substantially more important in determining community recovery than regional richness per se. Evidence supporting this argument is discussed in more detail below. However, our results clearly indicate that over the regional scale of our study, temperature has a great influence on the early development of disturbed communities, and may override the effects of other environmental and biotic factors. That recovery was greatest with increasing temperature is biologically intuitive and supported by extensive evidence indicating that temperature generally has a profound influence on species' metabolic rates (Gillooly et al. 2001), including algal growth rates (Lobban \& Harrison 1997).

Estimates of assemblage recovery extent, as determined in this study (via the Bray-Curtis index) can be influenced by 2 components of the assemblage structure: one relating to the composition of the species (presence or absence of species) and the other related to the relative abundance of species. We found that this distinction was important and helped our understanding of the recovery process in our study system, for instance by explaining the intermediate levels of similarity between disturbed and control plots found in the Azores.

Natural communities are generally dominated by a few common species and many relatively rare species (Gaston 1994, Kunin \& Gaston 1997). Given the importance of species identity to estimates of assemblage recovery extent, as used here, patterns of distribution of rare species were expected to explain potential differences in assemblage recovery. Yet, patterns of distribution of rare species were similar not only among regions, but also between disturbed and control plots, suggesting that regional-scale variation in the recovery of disturbed plots was associated with the common species. 
Over the past 4 decades there has been increasing recognition of the importance of species identity, rather than purely species numbers, in determining ecosystem processes (e.g. Harvey et al. 2013), including studies on macroalgae (Bruno et al. 2005, 2006). While the 3 regions are part of the Lusitania province, there are marked differences in species composition among them, especially between northern Portugal and the insular regions. For instance, northern Portugal is the southern limit of many coldtemperate, large, canopy-forming brown algae (e.g. Ascophyllum nodosum, Araújo et al. 2009b).

Canopy-forming algae are considered key habitat formers (ecosystem engineers, sensu Jones et al. 1994) that influence community structure via modifications of spatial complexity and the physical environment (e.g. temperature, shading; Reed \& Foster 1984, Duggins et al. 1990), and can influence assemblages both positively (e.g. ameliorating stress conditions) and negatively (space monopolization; Bertness et al. 1999, Jenkins et al. 1999, Bulleri et al. 2002). However, large canopy-forming algae generally have slow growth rates, taking a long time to fully recover biomass to pre-disturbed levels (e.g. Jenkins et al. 2004). Moreover, canopy-forming algae generally have short and well-defined periods of recruitment (Mathieson 1976, Hawkins 1981), which may influence the outcome of competitive interactions (e.g. Benedetti-Cecchi 2000). Two locations out of the 3 examined in northern Portugal were, indeed, dominated by leathery algae, in this case Bifurcaria bifurcata (see Fig. 6). Thus, it is not surprising that 12 mo after disturbance, the cover of B. bifurcata, a slow-growing alga, had not fully recovered. Even though the cover of $B$. bifurcata varied among locations in northern Portugal, its presence in the north appears to be the main reason accounting for the differences among regions in early patterns of recovery from disturbance; more specifically, the 'slower' recovery in northern Portugal compared to the Canary Islands.

Unlike northern Portugal, articulated corallines and a complex matrix of turf-forming algae dominate the lower shore in the Azores and Canary Islands. These turfs are generally composed of a myriad of small filamentous species, and composition varies considerably over small and large spatial scales (Airoldi 2001), reflecting variable patterns of recruitment through time (Coleman 2003). In contrast to leathery algae, turfs have the ability to quickly recover from disturbances and secure vacant space via rapid lateral vegetative growth (Airoldi 1998, Martins et al. 2010); this helps to explain the greater sim- ilarity between disturbed and control plots (and hence recovery) found in the Azores and Canary Islands.

In addition to the above, Viejo et al. (2008) showed that the experimental removal of ephemeral algae, mostly comprised of Ulva spp., positively affected the establishment of Fucus spp. and that this effect was more pronounced lower on the shore. That is, ephemeral algae can also have a negative effect on rate of assemblage recovery via inhibitory effects on the establishment of later-successional species (Jenkins \& Martins 2010). In our study, the abundance of sheetlike algae, mostly Ulva spp., was indeed significantly greater in northern Portugal compared to the other regions, especially in disturbed plots. This adds weight to the idea that regional-scale differences in community recovery extent can be affected by regional-scale differences in the abundance of key species. In fact, although eliminated from the model (due to strong collinearity with the other predictor variables), there was a significant and negative correlation between early patterns of assemblage recovery and productivity (chl a). This suggests that, at least during the early stages of community assembly, productivity may adversely influence the recovery process. A possible explanation is that high productivity promoted the proliferation of early successional ephemeral species such as Ulva spp. (as observed in northern Portugal), with inhibitory effects on the establishment of latesuccessional perennial species (Viejo et al. 2008).

A closer inspection of plots in northern Portugal supports the above arguments. At Aguda, where canopy species were naturally absent and the abundance of sheet-like algae was lower (see Fig. 6), similarity between disturbed and control plots was much higher than in the 2 other locations (see Fig. 3), and was more similar to some found in the Azores. These results reinforce the potential community-level influence of canopy species (Jenkins et al. 2008) and sheet-like algae (Viejo et al. 2008), suggesting that regional-scale differences in the spatial distribution of algal canopies and in the local abundance of ephemerals may actually be the key factors controlling the processes of community recovery from disturbances. The idea that a small number species can have a disproportionate community-level effect is deeply rooted in marine ecology (Paine 1969) and is often shown to be of greater importance than richness per se (e.g. O'Connor \& Crowe 2005).

It is interesting to note, however, that while the presence of canopy algae seems to play a key role in 'delaying' the recovery of disturbed communities, they can concomitantly have a positive effect on as- 
semblage resistance to disturbances (Bertocci et al. 2010). This duality of relationships (negative and positive) between the various components that make up ecological stability (e.g. resistance, recovery, compositional turnover) has been noted by Donohue et al. (2013). From a conservation point of view, our results suggest that recovery rates of low-shore algaldominated communities in the environments studied depend primarily on the presence of canopy-forming algae (and the abundance of ephemerals). Shores dominated by canopy-forming algae, although resistant to some types of disturbances (Bertocci et al. 2010), have a much lower recovery rate (resilience). Canopy-forming algae are an important component of coastal ecosystems sustaining many ecological functions and services (e.g. wave dissipation, shading), but are increasingly being replaced by algal turfs along urbanised coasts (e.g. Benedetti-Cecchi et al. 2001, Gorman et al. 2009). These results should be taken in consideration when planning the restoration of disturbed habitats.

From a restoration point of view, further studies should thus focus on identifying the context-dependencies of the influence of disturbance scale and its interactive effects with regional-scale differences in environmental conditions (e.g. temperature) on the recovery of disturbed communities.

Acknowledgements. This research was partially supported by the European Regional Development Fund (ERDF) through the COMPETE - Operational Competitiveness Programme and national funds through the Fundação para a Ciência e Tecnologia (FCT, Portugal), under the project 'PEst-C/MAR/LA0015/2011' and by the Spanish MINECO Plan Nacional' ANTROTIDAL (CGL2011-23833). G.M.M. was supported by a post-doctoral research grant awarded by FCT (SFRH/BDP/63040/2009); F.T. was supported by the MINECO Ramón y Cajal' program. The research staff of ULPGC was partially supported by the Campus Atlántico Tricontinental. This manuscript was substantially improved by the suggestions made by 3 anonymous reviewers.

\section{LITERATURE CITED}

Airoldi L (1998) Roles of disturbance, sediment stress, and substratum retention on spatial dominance in algal turf. Ecology 79:2759-2770

> Airoldi L (2001) Distribution and morphological variation of low-shore algal turfs. Mar Biol 138:1233-1239

Amorim P (2008) Spatial variability of seabird distribution associated with environmental factors: a case study of marine important bird areas in the Azores. ICES J Mar Sci 66:29-40

> Aquilino KM, Stachowicz JJ (2012) Seaweed richness and herbivory increase rate of community recovery from disturbance. Ecology 93:879-890

- Araújo R, Bárbara I, Tibaldo M, Berecibar E and others (2009a) Checklist of benthic marine algae and cyanobac- teria of northern Portugal. Bot Mar 52:24-46

Araújo R, Vaselli S, Almeida M, Serrão E, Sousa-Pinto I (2009b) Effects of disturbance on marginal populations: human trampling on Ascophyllum nodosum assemblages at its southern distribution limit. Mar Ecol Prog Ser 378:81-92

> Benedetti-Cecchi L (2000) Priority effects, taxonomic resolution, and the prediction of variable patterns of colonisation of algae in littoral rock pools. Oecologia 123:265-274

> Benedetti-Cecchi L, Pannacciulli F, Bulleri F, Moschella PS, Airoldi L, Relini G, Cinelli F (2001) Predicting the consequences of anthropogenic disturbance: large-scale effects of loss of canopy algae on rocky shores. Mar Ecol Prog Ser 214:137-150

> Bertness MD, Leonard GH, Levine JM, Schmidt PR, Ingraham AO (1999) Testing the relative contribution of positive and negative interactions in rocky intertidal communities. Ecology 80:2711-2726

Bertocci I, Arenas F, Matias M, Vaselli S and others (2010) Canopy-forming species mediate the effects of disturbance on macroalgal assemblages on Portuguese rocky shores. Mar Ecol Prog Ser 414:107-116

> Bruno JF, Boyer KE, Duffy JE, Lee SC, Kertesz JS (2005) Effects of macroalgal species identity and richness on primary production in benthic marine communities. Ecol Lett 8:1165-1174

Bruno JF, Lee SC, Kertesz JS, Carpenter RC, Long ZT, Duffy JE (2006) Partitioning the effects of algal species identity and richness on benthic marine primary production. Oikos 115:170-178

Bulleri F, Benedetti-Cecchi L, Acunto S, Cinelli F, Hawkins SJ (2002) The influence of canopy algae on vertical patterns of distribution of low-shore assemblages on rocky coasts in the northwest Mediterranean. J Exp Mar Biol Ecol 267:89-106

Bulleri F, Benedetti-Cecchi L, Cusson M, Maggi E and others (2012) Temporal stability of European rocky shore assemblages: variation across a latitudinal gradient and the role of habitat-formers. Oikos 121:1801-1809

> Coleman MA (2003) The role of recruitment in structuring patterns of small-scale spatial variability in intertidal and subtidal algal turfs. J Exp Mar Biol Ecol 291:131-145

> Coleman RA, Underwood AJ, Benedetti-Cecchi L, Åberg P and others (2006) A continental scale evaluation of the role of limpet grazing on rocky shores. Oecologia 147:556-564

Crisp DJ, Southward AJ (1958) The distribution of intertidal organisms along the coasts of the English Channel. J Mar Biol Assoc UK 37:1-208

Crowe TP, Cusson M, Bulleri F, Davoult D and others (2013) Large-scale variation in combined impacts of canopy loss and disturbance on community structure and ecosystem functioning. PLoS ONE 8:e66238

> Dayton PK (1971) Competition, disturbance, and community organization: the provision and subsequent utilization of space in a rocky intertidal community. Ecol Monogr 41: 351-389

Dethier MN, Graham ES, Cohen S, Tear LM (1993) Visual versus random-point percent cover estimations: 'objective' is not always better. Mar Ecol Prog Ser 96:93-100

> Donohue I, Petchey OL, Montoya JM, Jackson AL and others (2013) On the dimensionality of ecological stability. Ecol Lett 16:421-429

$>$ Dudgeon S, Petraitis PS (2001) Scale-dependent recruitment and divergence of intertidal communities. Ecology 82: 991-1006 
Duggins DO, Eckman JE, Sewell AT (1990) Ecology of understory kelp environments II. Effects of kelp on recruitment of benthic invertebrates. J Exp Mar Biol Ecol $143: 27-45$

Gaston KJ (1994) Rarity. Chapman \& Hall, London

Gillooly JF, Brown JH, West GB, Savage VM, Charnov EL (2001) Effects of size and temperature on metabolic rate. Science 293:2248-2251

> Gorman D, Russell BD, Connell SD (2009) Land-to-sea connectivity: linking human-derived terrestrial subsidies to subtidal habitat change on open rocky coasts. Ecol Appl 19:1114-1126

> Harvey E, Séguin Am Nozais C, Archambault P, Gravel D (2013) Identity effects dominate the impacts of multiple species extinctions on the functioning of complex food webs. Ecology 94:169-179

Hawkins SJ (1981) The influence of season and barnacles on algal colonization of Patella vulgata (L.) exclusion areas. J Mar Biol Assoc UK 61:1-15

> Hawkins SJ, Corte-Real HBSM, Pannacciulli FG, Weber LC (2000) Thoughts on the ecology and evolution of the intertidal biota of the Azores and other Atlantic islands. Hydrobiologia 440:3-17

> Hernández-Léon S (1988) Gradients of mesozooplankton biomass and ETS activity in the wind-shear area as evidence of an island mass effect in the Canary Island waters. J Plankton Res 10:1141-1154

Hewitt JE, Thrush SF, Dayton PK, Bonsdorff E (2007) The effect of spatial and temporal heterogeneity on the design and analysis of empirical studies of scale-dependent systems. Am Nat 169:398-408

Instituto Hidrográfico (2000) Roteiro da costa de Portugal: Arquipélago dos Açores. Instituto Hidrográfico, Lisboa

Jenkins SR, Martins GM (2010) Succession on hard substrata. In: Dürr S, Thomason JC (eds) Biofouling. WileyBlackwell, Chichester, p 60-72

Jenkins SR, Hawkins SJ, Norton TA (1999) Direct and indirect effects of a macroalgal canopy and limpet grazing in structuring a sheltered inter-tidal community. Mar Ecol Prog Ser 188:81-92

$>$ Jenkins SR, Norton TA, Hawkins SR (2004) Long term effects of Ascophyllum nodosum canopy removal on mid shore community structure. J Mar Biol Assoc UK 84:327-329

> Jenkins SR, Moore P, Burrows MT, Garbarry DJ and others (2008) Comparative ecology of North Atlantic shores: Do differences in players matter for processes? Ecology 89: S3-S23

> Jones CG, Lawton JH, Shachak M (1994) Organisms as ecosystem engineers. Oikos 69:373-386

Kunin WE, Gaston KJ (1997) The biology of rarity: causes and consequences of rare-common differences. Chapman \& Hall, London

Lima F, Ribeiro PA, Queiroz N, Hawkins SJ, Santos A (2007) Do distributional shifts of northern and southern species of algae match the warming pattern? Glob Change Biol 13:2592-2604

Lobban CS, Harrison PJ (1997) Seaweed ecology and physiology. Cambridge University Press, Cambridge

> Martins AM, Amorim ASB, Figueiredo MP, Sousa RJ, Mendonça AP, Bashmachnikov IL, Carvalho DS (2007) Sea surface temperature (AVHRR, MODIS) and ocean colour (MODIS) seasonal and interannual variability in the Macaronesian islands of Azores, Madeira, and Canaries. Proc SPIE 6743:67430A-1

Martins GM, Thompson RC, Neto AI, Hawkins SJ, Jenkins SR (2010) Exploitation of intertidal grazers as a driver of community divergence. J Appl Ecol 47:1282-1289
Mathieson AC (1976) Seasonal growth and reproduction of estuarine fucoid algae in New England. J Exp Mar Biol Ecol 25:273-284

> Menge BA, Sanford E, Daley BA, Freidenburg TL, Hudson G, Lubchenco J (2002) Inter-hemispheric comparison of bottom-up effects on community structure: insights revealed using the comparative-experimental approach. Ecol Res 17:1-16

> Navarrete SA, Wieters EA, Broitman BR, Castilla JC (2005) Scales of benthic-pelagic coupling and the intensity of species interactions: from recruitment limitation to topdown control. Proc Natl Acad Sci USA 102:18046-18051

Navarro PG, García-Sanz S, Tuya F (2012) Reproductive biology of the sea cucumber Holothuria sanctori (Echinodermata: Holothuroidea). Sci Mar 76:741-752

$>$ O'Connor NE, Crowe TP (2005) Biodiversity loss and ecosystem functioning: distinguishing between number and identity of species. Ecology 86:1783-1796

Paine RT (1969) A note on trophic complexity and community stability. Am Nat 103:91-93

Petraitis PS, Latham RE (1999) The importance of scale in testing the origins of alternative community states. Ecology 80:429-442

Quinn GP, Keough MJ (2002) Experimental design and data analysis for biologists. Cambridge University Press, Cambridge

> Reed DC, Foster MS (1984) The effects of canopy shading on algal recruitment and growth in a giant kelp forest. Ecology 65:937-948

Santos F, Gómez-Gesteira M, deCastro M, Álvarez I (2011) Upwelling along the western coast of the Iberian Peninsula: dependence of trends on fitting strategy. Clim Res 48:213-218

> Sisodia S, Singh BN (2010) Influence of developmental temperature on cold shock and chill coma recovery in Drosophila ananassea: acclimatation and latitudinal variations among Indian populations. J Therm Biol 35: $117-124$

Steneck RS, Dethier MN (1994) A functional group approach to the structure of algal dominated communities. Oikos 69:476-498

Tilman D, Downing AJ (1994) Biodiversity and stability in grasslands. Nature 367:363-365

Tuya F, Haroun RJ (2006) Spatial patterns and response to wave exposure of shallow water algal assemblages across the Canarian Archipelago: a multi-scaled approach. Mar Ecol Prog Ser 311:15-28

Tuya F, Haroun RJ (2009) Phytogeography of Lusitanian Macaronesia: biogeographic affinities in species richness and assemblage composition. Eur J Phycol 44:405-413

Tuya F, Ramírez R, Sánchez-Jerez P, Haroun RJ, GonzálezRamos AJ, Coca J (2006) Coastal resources exploitation can mask bottom-up mesoscale regulation of intertidal populations. Hydrobiologia 553:337-344

Tuya F, Cacabelos E, Duarte P, Jacinto D and others (2012) Patterns of landscape and assemblage structure along a latitudinal gradient in ocean climate. Mar Ecol Prog Ser 466:9-19

Underwood AJ (1997) Experiments in ecology: their logical design and interpretation using analysis of variance. Cambridge University Press, Cambridge

Viejo RM, Arenas F, Fernández C, Gómez M (2008) Mechanisms of succession along the emersion gradient in intertidal rocky shore assemblages. Oikos 117:376-389

Wilson SD, Tilman D (2002) Quadratic variation in old-field species richness along gradients of disturbance and nitrogen. Ecology 83:492-504 